Article

\title{
Mycotoxin Removal by Lactobacillus spp. and Their Application in Animal Liquid Feed
}

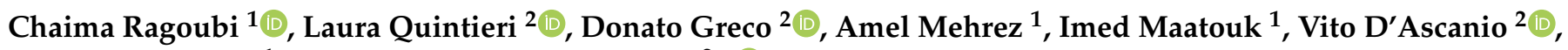 \\ Ahmed Landoulsi ${ }^{1}$ and Giuseppina Avantaggiato ${ }^{2, *(D)}$ \\ 1 Risques liés aux Stress Environnement aux, Lute et Prévention, Faculté des Sciences de Bizerte, \\ Université de Carthage, Zarzouna 7021, Tunisia; chaymaragoubi9@gmail.com (C.R.); \\ mehrezamel@yahoo.fr (A.M.); maatoukimed@yahoo.fr (I.M.); ahmed_landoulsi@yahoo.fr (A.L.) \\ 2 Institute of Sciences of Food Production, National Research Council of Italy, 70126 Bari, Italy; \\ laura.quintieri@ispa.cnr.it (L.Q.); donato.greco@ispa.cnr.it (D.G.); vito.dascanio@ispa.cnr.it (V.D.) \\ * Correspondence: giuseppina.avantaggiato@ispa.cnr.it
}

Citation: Ragoubi, C.; Quintieri, L.; Greco, D.; Mehrez, A.; Maatouk, I.; D'Ascanio, V.; Landoulsi, A.; Avantaggiato, G. Mycotoxin Removal by Lactobacillus spp. and Their Application in Animal Liquid Feed. Toxins 2021, 13, 185. https://doi.org/ $10.3390 /$ toxins 13030185

Received: 30 December 2020

Accepted: 25 February 2021

Published: 2 March 2021

Publisher's Note: MDPI stays neutral with regard to jurisdictional claims in published maps and institutional affiliations.

Copyright: (c) 2021 by the authors. Licensee MDPI, Basel, Switzerland. This article is an open access article distributed under the terms and conditions of the Creative Commons Attribution (CC BY) license (https:/ / creativecommons.org/licenses/by/ $4.0 /)$.

\begin{abstract}
The removal of mycotoxins from contaminated feed using lactic acid bacteria (LAB) has been proposed as an inexpensive, safe, and promising mycotoxin decontamination strategy. In this study, viable and heat-inactivated L. acidophilus CIP 76.13T and L. delbrueckii subsp. bulgaricus CIP $101027 \mathrm{~T}$ cells were investigated for their ability to remove aflatoxin $\mathrm{B}_{1}\left(\mathrm{AFB}_{1}\right)$, ochratoxin $\mathrm{A}(\mathrm{OTA})$, zearalenone (ZEA), and deoxynivalenol (DON) from MRS medium and PBS buffer over a $24 \mathrm{~h}$ period at $37^{\circ} \mathrm{C}$. LAB decontamination activity was also assessed in a ZEA-contaminated liquid feed (LF). Residual mycotoxin concentrations were determined by UHPLC-FLD/DAD analysis. In PBS, viable L. acidophilus CIP 76.13T and L. delbrueckii subsp. bulgaricus CIP 101027 T cells removed up to $57 \%$ and $30 \%$ of ZEA and DON, respectively, while $\mathrm{AFB}_{1}$ and OTA reductions were lower than $15 \%$. In MRS, $28 \%$ and $33 \%$ of $Z E A$ and $A_{F B}$ were removed, respectively; OTA and DON reductions were small $(\leq 15 \%)$. Regardless of the medium, heat-inactivated cells produced significantly lower mycotoxin reductions than those obtained with viable cells. An adsorption mechanism was suggested to explain the reductions in $\mathrm{AFB}_{1}$ and OTA, while biodegradation could be responsible for the removal of ZEA and DON. Both viable LAB strains reduced ZEA by $23 \%$ in contaminated LF after $48 \mathrm{~h}$ of incubation. These findings suggest that LAB strains of L. acidophilus CIP 76.13T and L. delbrueckii subsp. bulgaricus CIP 101027T may be applied in the feed industry to reduce mycotoxin contamination.
\end{abstract}

Keywords: mycotoxins; lactic acid bacteria; liquid feed; decontamination; adsorption; biodegradation; desorption

Key Contribution: Two potential probiotic LAB strains, L. acidophilus CIP: 76.13T and L. delbrueckii subsp. bulgaricus CIP: 101027T are able to remove mycotoxins (OTA, ZEA, DON, and AFB1) in in vitro experiments and in an animal LF used as a feed model. An experimental procedure to study the mechanism of mycotoxin removal (adsorption or metabolism) by bacterial strains is presented.

\section{Introduction}

Mycotoxins are harmful secondary metabolites produced by fungi that contaminate a wide range of food and feed products [1-3]. Depending on the frequency of occurrence and/or the severity of the disease that they produce, mycotoxins belonging to the aflatoxin, ochratoxin, and Fusarium toxin groups exert great impacts on animal/human health as well as on global trade $[2,4]$. Aflatoxin $B_{1}\left(A_{F B}\right)$, zearalenone (ZEA), ochratoxin A (OTA), and deoxynivalenol (DON) are the most commonly occurring mycotoxins. They can cause a variety of diseases (mycotoxicoses) in a wide range of susceptible animal species [2,4]. Pigs are one of the most sensitive species to mycotoxins. These mycotoxins can cause both clinical and subclinical effects, including depressed food intake, impaired gut integrity, vaccination failure, liver overload, immune system interference, and damage to immune 
system cells, as well as acting as predisposing factors to infectious agents present on the farm. The presence of mycotoxins in feed can result in the poor performance of animals. The effects of mycotoxins depend on the health status, duration of exposure, nutrition, and co-occurrence of different toxins in the animals that consume them. When natural contamination with mycotoxins occurs, co-occurrence of more than one mycotoxin is likely to occur. According to a recent extensive global survey [5], almost $90 \%$ of feed and raw feed materials collected worldwide were found to be positive for at least one mycotoxin. Contamination with multiple mycotoxins was found in a large fraction of these samples (64\%). Mycotoxin co-contamination depends mainly on the geographic region, climate, and weather conditions and can lead to the enhancement of the overall toxic effect of a single mycotoxin (synergistic effects) [6]. Therefore, despite most of the sample complying with the maximum levels/guidance values for mycotoxins in feed established in the European Union [7,8], the effect of mycotoxin co-occurrence on animal performance must be addressed $[9,10]$. Considering potential economic losses that mycotoxins can impose, highly efficient mycotoxin decontamination represents a crucial challenge. Several strategies, including physical, chemical, and biological methods, have been proposed to eliminate, inactivate, or reduce the mycotoxin concentration in food and feed commodities [11-15]. The application of traditional physical and chemical methods has some limitations concerning safety issues and losses in the nutritional value and palatability of feeds, coupled with limited efficacy and cost implications $[12,16]$. In contrast, biological decontamination involving the use of microorganisms or enzymatic extracts to facilitate biodegradation of the toxins and reduction of their absorption in the human and animal gastrointestinal tracts represents a sustainable approach that could be applied in the food and feed industries $[11,13,14,17]$. In addition, biological decontamination can be considered a suitable and valuable method for the decontamination of feed products intended to be used in the liquid state.

Liquid feed (LF) is a mixture of by-products from the liquid food industry and conventional dry materials or is made from dry raw materials mixed with water [18]. This alternative feeding strategy is widely used to improve animal health and performance, since it has several advantages, including simultaneous feed and water intake and positive effects on the animal gastrointestinal microflora [19-23]. LF manufacturing processes can also include fermentation with microorganisms, such as lactic acid bacteria (LAB), which have technological and functional properties that can improve feed safety and animal health by reducing the incidence of most common diseases [23-25]. However, as solid feed products, LFs can be contaminated by mycotoxins. High levels of mycotoxins have been detected in food by-products used as ingredients for food-based LFs [26-28]. The levels of DON and ZEA were found to exceed their limits in liquid pig feed [26].

LAB are typically associated with intestinal microflora and are also classified as probiotics due to their health effects in humans [29] and animals [30-32]. Many research reports have demonstrated their potential to either degrade mycotoxins or reduce their bioavailability in humans and animals [33-35]. The enteric bacteria Lactobacillus rhamnosus and L. acidophilus, as well as the plant-associated bacteria L. plantarum, L. brevis, and L. sanfranciscensis have been shown to have a high toxin decontamination ability $[33,34,36]$. To the best of our knowledge, few studies have reported on the reduction of mycotoxins in feed by LAB $[37,38]$.

The aim of this work was to investigate the ability of some LAB strains isolated from healthy human urine (L. acidophilus CIP: 76.13T) and food products (L. delbrueckii subsp. bulgaricus CIP: 101027T) to reduce the main mycotoxins occurring in agricultural raw materials and food waste, i.e., $\mathrm{AFB}_{1}, \mathrm{ZEA}, \mathrm{OTA}$, and DON. In a preliminary study, one of these strains (L. acidophilus CIP: 76.13T) was found to be a promising probiotic due to its technological characteristics [39]. To evaluate the use of L. acidophilus CIP: 76.13T and L. delbrueckii subsp. bulgaricus CIP: $101027 \mathrm{~T}$ in a decontamination strategy to minimize the risk of mycotoxin contamination of animal feed, both strains were assessed in a LF intended for pig feed. 


\section{Results and Discussion}

\subsection{Effect of Mycotoxins on $L A B$ Growth}

In order to assess the effect of mycotoxins on bacterial growth and viability, the growth of $\mathrm{LAB}$ was monitored in the presence and absence of the toxins, and the results were compared. As shown in Figure 1, the growth of L. acidophilus CIP: 76.13T was slightly inhibited by DON and OTA during the first $6 \mathrm{~h}$ of incubation $(p<0.05)$. In the presence of these mycotoxins, the microbial load of L. acidophilus CIP: 76.13T was reduced by ca. $1 \log \mathrm{cfu} / \mathrm{mL}$ in comparison to that of the control samples $(p<0.003)$. Likewise, DON affected the growth of L. delbrueckii subsp. bulgaricus CIP: 101027T, causing a reduction in growth of $2 \log \mathrm{cfu} / \mathrm{mL}$ after $6 \mathrm{~h}$ of incubation $(p<0.001)$ (Figure 1). After $24 \mathrm{~h}$ of incubation, no growth difference was registered when LAB strains were cultured in media supplemented (or not) with the mycotoxins. These findings agree with previous works showing that most mycotoxins do not inhibit the growth of Lactobacillus strains [40,41]. Recently, a dose-dependent inhibitory effect on the microbial load of Lactobacillus spp. was registered in mice gut microbiota after exposure to DON [42].
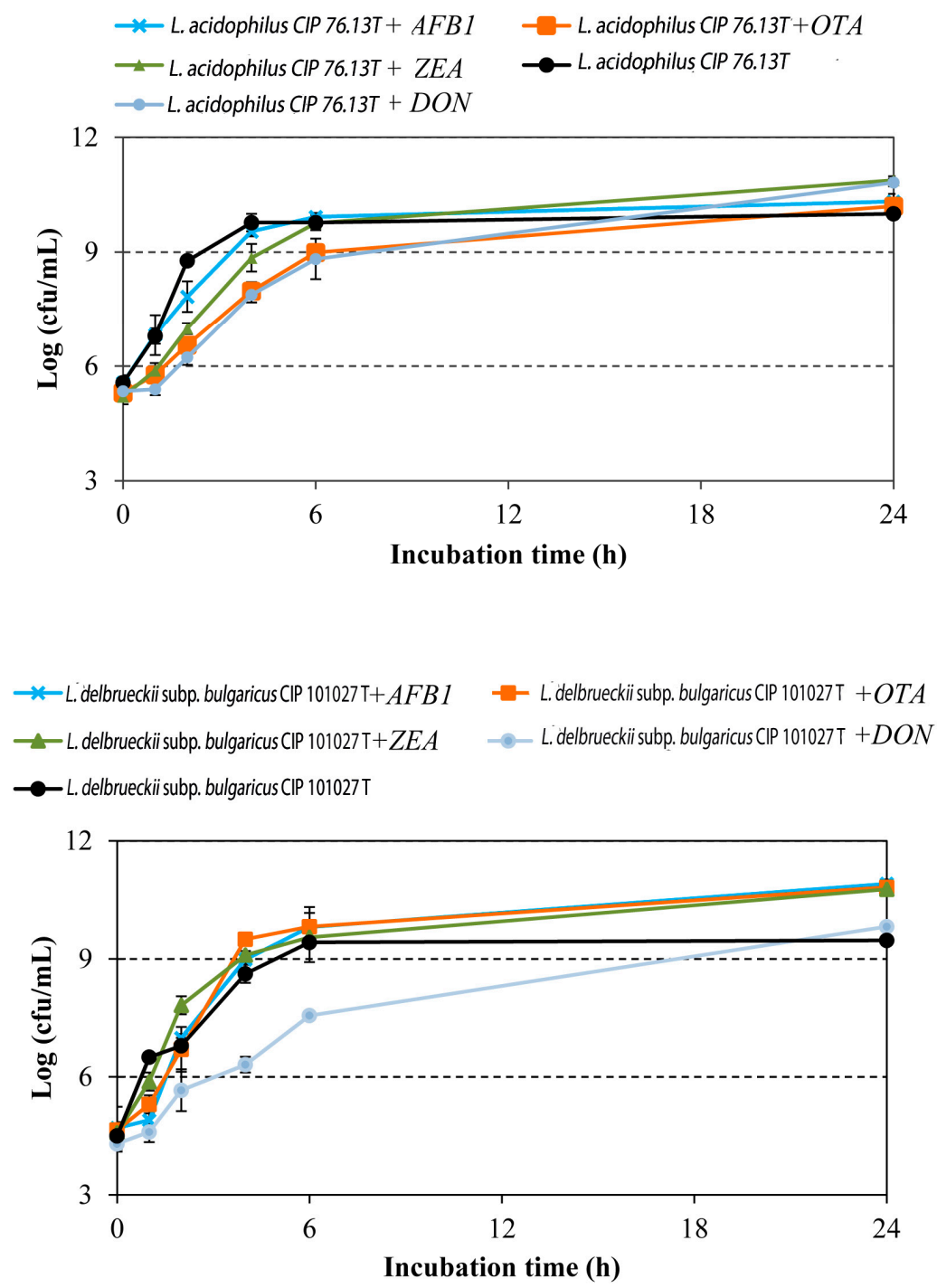

Figure 1. Growth curves of L. acidophilus CIP: 76.13T and L. delbrueckii subsp. bulgaricus CIP: 101027T obtained in MRS at $37^{\circ} \mathrm{C}$ for $24 \mathrm{~h}$ in the absence or presence of target mycotoxins (aflatoxin $\mathrm{B}_{1}$ (AFB1), ochratoxin A (OTA), zearalenone (ZEA), and deoxynivalenol (DON)). The mycotoxin concentration was $1 \mu \mathrm{g} / \mathrm{mL}$. Values are presented as means \pm standard deviations $(n=3)$. 


\subsection{Mycotoxin Removal by LABs}

In the current study, the ability of L. acidophilus CIP: 76.13T and L. delbrueckii subsp. bulgaricus CIP: 101027T to remove mycotoxins, i.e., $\mathrm{AFB}_{1}$, OTA, ZEA, and DON was assessed in two different media, MRS and PBS. In particular, PBS was used to evaluate the ability of LAB to reduce the concentrations of the targeted mycotoxins in the absence of a carbon source or other nutrients.

The results of the microbiological analysis showed that the MRS microbial load reached an average level of $10 \log \mathrm{cfu} / \mathrm{mL}$ after $24 \mathrm{~h}$ of incubation, while in PBS, a constant value was registered throughout the incubation period- $5.5 \log \mathrm{cfu} / \mathrm{mL}$ and $6 \log \mathrm{cfu} / \mathrm{mL}$ (on average) at the beginning and the end of the assay, respectively. The final $\mathrm{pH}$ values in MRS and PBS were 4.2 and 6.0, respectively. As expected, bacterial growth in MRS was accomplished by a change in the $\mathrm{pH}$ value of the liquid medium caused by the formation of organic acids. No viable cells were found after the heat treatment of cell pellets.

As previously documented [43], mycotoxin removal by bacterial strains can occur in two ways: by biodegradation or transformation of the molecules and/or by adsorption into the cell walls of bacteria. To assess whether one or both mechanisms are involved in the removal of mycotoxins by our LAB strains, experiments using viable and thermally inactivated bacterial cells and desorption trials were carried out. Experimental results of mycotoxin removal expressed as percentages that were obtained using viable or inactivated L. acidophilus CIP: 76.13T and L. delbrueckii subsp. bulgaricus CIP: 101027T cells harvested in MRS and PBS are summarized in Table 1. (The related residual concentration values are also reported in Supplementary Table S1).

Except for ZEA, small reductions were registered for most mycotoxins (Table 1). The maximal OTA removal ability with viable cells was observed for L. delbrueckii subsp. bulgaricus CIP: 101027T (15\%) in MRS, while OTA reduction values not higher than $8 \%$ were obtained when these cells were harvested in PBS. A slight increase in the removal activity of OTA was found after incubating heat-inactivated cells in PBS $(p=0.033)$. In this buffer, heat-inactivated L. acidophilus CIP: 76.13T and L. delbrueckii subsp. bulgaricus CIP: $101027 \mathrm{~T}$ cells reduced the toxin concentration by $13 \%$ and $23 \%$, with L. delbrueckii subsp. bulgaricus CIP: $101027 \mathrm{~T}$ being the most efficient species $(p=0.033)$. Our results are in accordance with the outcomes of the study performed by Piotrowska [39], which examined the removal of OTA by three LAB, L. plantarum, L. brevis, and L. sanfranciscensis, in MRS and PBS, using viable or thermally inactivated bacterial cells. A study by Piotrowska [39] reports that OTA reduction was higher in thermally inactivated bacterial cells, suggesting that the toxin has a binding mechanism. Higher OTA adsorption by heat-inactivated rather than live cells in PBS was explained by changes occurring in the bacterial cell wall induced by high temperature [39]. Taking into account the study by Piotrowska [44], we suggest that our L. acidophilus CIP: 76.13T and L. delbrueckii subsp. bulgaricus CIP: 101027T strains can bind OTA to the surface structures of the cell wall. In addition to OTA, both LAB strains reduced $\mathrm{AFB}_{1}$ in MRS and PBS $(p<0.05)($ Table 1$)$ in a similar manner. In particular, after $24 \mathrm{~h}$ of incubation, viable L. acidophilus CIP: $76.13 \mathrm{~T}$ and L. delbrueckii subsp. bulgaricus CIP: $101027 \mathrm{~T}$ cells removed $34 \%$ and $31 \%$ of $\mathrm{AFB}_{1}$ in MRS and $6 \%$ and $16 \%$ in PBS $(p=0.024)$. As observed for OTA, the removal of $\mathrm{AFB}_{1}$ obtained by testing viable cells in MRS was significantly higher compared to in PBS $(p<0.001)$ (Table 1$)$. This result may be related to the higher microbial concentration recorded in MRS than in PBS. In addition, in both MRS and $\mathrm{PBS}, \mathrm{AFB}_{1}$ reductions obtained using thermally inactivated cells were comparable with those obtained using viable cells. Therefore, we suggest that adsorption is the mechanism that drives $\mathrm{AFB}_{1}$ removal by our strains. Cell wall binding of $\mathrm{AFB}_{1}$ by LAB is the most frequently described mechanism in the literature [35,45-47].

While adsorption seems to occur when OTA or $\mathrm{AFB}_{1}$ are incubated in contaminated liquid media inoculated with the herein tested strains, other mechanisms may be involved in the reduction of ZEA and DON.

As shown in Table 1, small removal values were recorded for DON when viable or heat-treated cells of L. acidophilus CIP: 76.13T and L. delbrueckii subsp. bulgaricus CIP: 
101027T were tested in MRS, with these values being in the range of 3-9\%. The strains did not differ in their ability to remove the toxin $(p>0.05)$. Higher values of DON reduction were obtained when viable or heat-inactivated cells from the strains were cultured in PBS. In this buffer, the L. acidophilus CIP: 76.13T and L. delbrueckii subsp. bulgaricus CIP: $101027 \mathrm{~T}$ strains removed $31 \%$ and $30 \%$ of DON in the viable form and $14 \%$ and $19 \%$ in the heat-inactivated form $(p<0.001)$.

The percentage of ZEA removal by LAB strains ranged from 11 to 57\%, depending on the culture medium and bacterial viability state. Similar to the results observed for DON, no significant difference was recorded between strains for their ZEA removal efficacy $(p>0.05)$. The highest ZEA removal values were registered in PBS by testing viable cells: 57\% and 56\% for L. acidophilus CIP: 76.13T and L. delbrueckii subsp. bulgaricus CIP: 101027T, respectively. In contrast, in MRS, for these strains and in the viable state, the average ZEA reduction value did not exceed $28 \%$. Regardless of the medium and strain used, the efficacy of viable cells in reducing ZEA was significantly higher compared with heat-inactivated cells $(p<0.001)$. The level of ZEA removal by heat-inactivated cells was comparable in MRS and PBS, with values being $11-12 \%$ in MRS and $12-13 \%$ in PBS.

Taking into account the overall results for DON and ZEA reduction and considering that the removal of these mycotoxins in liquid media was significantly higher when viable cells of the LAB were tested or when a mineral buffer (PBS) was used where the mycotoxins were the only carbon source in the growth medium, we can assume that ZEA and DON are removed by a biodegradation mechanism. Our data agree with those reported by Chen et al. [48], who described LAB estereolitic activity as being based on ZEA degradation with no release of toxic metabolites. Regarding DON, the reduction percentage values registered for our strains fell within the range of those reported by other authors [49]. In addition, Garcia et al. [50] found that in PBS, the reduction in the DON concentration by $\mathrm{LAB}$ was due to the activity of extracellular enzymes that have not yet been identified. In order to confirm this mechanism and exclude the presence of an adsorption process on the cell walls of the strains, a desorption assay was performed for LAB cells incubated in PBS. These trials were performed for ZEA only, as this was selected as the most reduced toxin in our experimental conditions. Desorption trials are intended to determine the amount of toxin adsorbed onto bacterial cells and released when the adsorbent pellets are resuspended with an organic solvent. Indeed, in the case of mycotoxin reduction caused by an adsorption process, the solvent used for the desorption assay extracts the toxin from the pellet, and then its presence in the supernatant can be determined following centrifugation [51]. In our study, a mixture containing acetonitrile and water $(9: 1 v / v)$ was used to release ZEA from the adsorbent pellets of LAB, being the most commonly used solvent for ZEA analysis in food and feed samples. Whether other mechanisms, such as metabolization, underlie the reduction of ZEA by LABs, it cannot be detected in the supernatants.

The results of the desorption study are presented in Table 2. Experimental values expressed as percentages refer to the amount of toxin released by the solvent with respect to the amount of ZEA reduced in PBS. As described above (Table 1), cells from viable L. acidophilus CIP: 76.13T and L. delbrueckii subsp. bulgaricus CIP: 101027T strains reduced ZEA by $57 \%$ and $56 \%$ in PBS $(p<0.001$ ). A negligible amount of toxin was released when the adsorbent pellets from these bacteria were treated with the organic solvent. For both LAB strains, the amount of ZEA desorbed from viable cells did not exceed $2 \%(p<0.001)$ (Table 2). In contrast, heat-treated cells from L. acidophilus CIP: 76.13T and L. delbrueckii subsp. bulgaricus CIP: 101027 T strains reduced the toxin concentration by only $13 \%$ and $12 \%$ in PBS $(p<0.001)$, respectively, and almost all of the adsorbed toxin was released. For these strains, the desorption values were $56 \%$ and $83 \%$, respectively. Based on the results obtained from adsorption and desorption trials, we can conclude that both mechanisms, biodegradation and adsorption of ZEA, can occur when the LAB strains are incubated with the toxin in PBS, depending on their state. In particular, viable cells from the strains reduce the toxin by biodegradation, especially in a medium in which ZEA is the only source of 
carbon. Therefore, the toxin cannot be recovered from the cell pellets in desorption trials. In addition, a lower amount of toxin can be reduced by adsorption, which occurs when cells are killed by heat treatment.

Several studies have reported the ability of LAB to reduce the mycotoxin concentration by adsorption and enzymatic degradation processes [33], which are both promising approaches for the decontamination of mycotoxin-contaminated foodstuffs. However, bacterial biodegradation of mycotoxins is believed to be the best solution to prevent the toxic effects of mycotoxins, since the possibility of release of the bound mycotoxins from the cell wall is an inherent disadvantage of the microbial adsorption mechanism which cannot be disregarded. As underlined by Chen et al. [48], microbial biodegradation of ZEN as a means of food and/or feed detoxification has not been studied extensively. This may be due to the lack of information concerning the mechanisms of biodegradation, the toxicity of the degradation products, and the safety of the microorganisms for animals. Recently, esterase activity by selected LAB strains belonging to the L. plantarum species was demonstrated to play a role in ZEA removal [48]. Metabolites produced by these hydrolytic enzymes act as substrates for metabolic pathways, sustaining microbial survival in PBS medium. Regarding ZEA removal, no related metabolites (i.e., $\alpha$ - and $\beta$-zearalenol, zearalanone and its reduced metabolites $\alpha$ - and $\beta$-zearalanol) were detected in inoculated MRS and PBS at the end of the incubation period. Although the mechanism of mycotoxin removal and the optimization of culture conditions for microbial growth need deeper investigation, the application of our strains, preferably as viable cells, in the preparation of animal feed may help to counteract the toxic effects of mycotoxins and to promote additional probiotic properties responsible for maintaining a healthy gastro-intestinal tract. Indeed, one of our LAB strains, L. acidophilus CIP 76.13, was previously investigated for its technological and probiotic properties; in particular, it exhibited high proteolytic and lipolytic activities and tolerance at several $\mathrm{pH}$ values $(\mathrm{pH} 3,5,7)[39]$.

\subsection{ZEA Removal in Animal Liquid Feed}

Taking into account the overall results of the study, the L. acidophilus CIP: 76.13T and L. delbrueckii subsp. bulgaricus CIP: 101027T strains were further tested to assess their efficacy to reduce ZEA in a liquid feed model.

The recovery and repeatability of the method used to analyze ZEA in LF were determined by spiking blank LF with different concentrations of the toxin. As shown in Table 3, this method was found to be satisfactory as it provided a recovery level of $92 \%$ for the highest mycotoxin concentration $(1 \mu \mathrm{g} / \mathrm{mL})$ and $81 \%$ for the lowest one $(0.1 \mu \mathrm{g} / \mathrm{mL})$. The within-day precision expressed as the relative standard deviation $\left(\mathrm{RSD}_{\mathrm{r}}\right)$ was also satisfying, being lower than $7 \%$. 


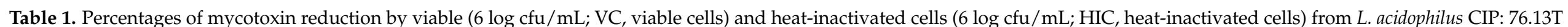

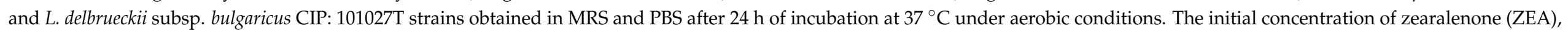
deoxynivalenol (DON), aflatoxin B1 ( $\left.\mathrm{AFB}_{1}\right)$, and ochratoxin $\mathrm{A}(\mathrm{OTA})$ in MRS and PBS was $1 \mu \mathrm{g} / \mathrm{mL}$ in all cases.

\begin{tabular}{|c|c|c|c|c|c|c|c|c|}
\hline \multicolumn{9}{|c|}{ Mycotoxin Reduction (\%) } \\
\hline \multirow{2}{*}{ LAB Strain } & \multicolumn{2}{|c|}{ ZEA } & \multicolumn{2}{|c|}{ DON } & \multicolumn{2}{|c|}{$\mathrm{AFB}_{1}$} & \multicolumn{2}{|c|}{ OTA } \\
\hline & MRS & PBS & MRS & PBS & MRS & PBS & MRS & PBS \\
\hline VC L. delbrueckii subsp. bulgaricus CIP: $101027 \mathrm{~T}$ & $28.5 \pm 1.8$ ay & $56.4 \pm 4.2 \mathrm{az}$ & $5.4 \pm 0.8$ aby & $30.0 \pm 0.5^{a z}$ & $30.8 \pm 3.6$ ay & $15.9 \pm 1.4 \mathrm{bz}$ & $15.3 \pm 2.5$ by & $4.0 \pm 1.2 \mathrm{az}$ \\
\hline HIC L. acidophilus CIP: $76.13 \mathrm{~T}$ & $11.9 \pm 1.8$ by & $12.8 \pm 4.3$ by & $3.1 \pm 0.8$ by & $14.1 \pm 1.1^{\mathrm{bz}}$ & $27.4 \pm 1.9$ aby & $11.9 \pm 2.4^{b z}$ & $2.2 \pm 2.5^{\mathrm{cy}}$ & $13.2 \pm 1.0^{\mathrm{bz}}$ \\
\hline HIC L. delbrueckii subsp. bulgaricus CIP: 101027T & $10.7 \pm 1.8$ by & $11.7 \pm 3.8$ by & $6.8 \pm 2.4^{\text {aby }}$ & $19.4 \pm 4.8^{\mathrm{bz}}$ & $22.8 \pm 0.5$ by & $14.3 \pm 2.4^{b z}$ & $1.1 \pm 0.9^{\mathrm{cy}}$ & $22.5 \pm 3.4^{c z}$ \\
\hline
\end{tabular}

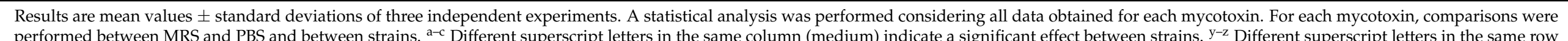
(strain) indicate a significant effect between media (ANOVA, Duncan test with $p<0.05$ representing significance). 
Table 2. Percentages of zearalenone (ZEA) desorbed from viable cells (VC) and heat-inactivated cells (HIC) of the L. acidophilus CIP: 76.13T and L. delbrueckii subsp. bulgaricus CIP: 101027T strains. Desorption data are given as means \pm standard deviations of three independent experiments.

\begin{tabular}{lcc}
\hline \multirow{2}{*}{ LAB Strain } & \multicolumn{2}{c}{ ZEA Desorbed (\%) } \\
\cline { 2 - 3 } & VC & HIC \\
\hline L. acidophilus CIP: 76.13T & $1.9 \pm 0.5^{\mathrm{a}}$ & $55.5 \pm 2.2^{\mathrm{b}}$ \\
L. delbrueckii subsp. bulgaricus CIP: 101027T & $1.9 \pm 0.2^{\mathrm{a}}$ & $82.9 \pm 5.4^{\mathrm{c}}$ \\
\hline
\end{tabular}

Values labeled with different superscript letters are significantly different (ANOVA, Duncan test with $p<0.05$ representing significance).

Table 3. Results of the validation study of the analytical method used to assess the zearalenone (ZEA) concentration in an animal liquid feed (LF). Mean recoveries and within-day relative standard deviations were obtained from spiked samples that were analyzed six times at each spiking level.

\begin{tabular}{cc}
\hline Spiking Level $(\mu \mathrm{g} / \mathrm{mL})$ & $\begin{array}{c}\text { Recovery \% } \\
\left.\text { (RSD }_{\mathbf{r}}, \%\right)\end{array}$ \\
\hline 0.1 & $81(7)$ \\
1.0 & $92(6)$ \\
\hline
\end{tabular}

L. acidophilus CIP: 76.13T and L. delbrueckii subsp. bulgaricus CIP: 101027T strains grew well in LF, reaching concentrations of 7.5 and $9.5 \log \mathrm{cfu} / \mathrm{mL}$ after $24 \mathrm{~h}$ of incubation at $37^{\circ} \mathrm{C}$ (Table 4). The percentages of ZEA removed by L. acidophilus CIP: 76.13T after 24 and $48 \mathrm{~h}$ of incubation were $14 \%$ and $22 \%(p=0.016)$, respectively. L. delbrueckii subsp. bulgaricus CIP: 101027T showed the same trend for toxin removal (10\% reduction after $24 \mathrm{~h}$ and $23 \%$ after $48 \mathrm{~h})(p=0.004)$ (Table 4 and Supplementary Table S2).

The level of efficacy of our LAB strains in removing ZEA in a complex environment, such as from a feed in liquid form, was comparable to that recorded in MRS. However, ZEA removal in MRS or LF was lower than the level of toxin reduction obtained with PBS. This may be explained by the interfering processes exerted by some components of the culture media. In addition, the negative effect of the final $\mathrm{pH}$ of bacterial cultures could have also played a role. As observed when MRS or LF was used as the growth media, at the end of the incubation period, bacterial cultures reached $\mathrm{pH}$ values lower than 5. Many studies have shown that culture conditions, such as the temperature, $\mathrm{pH}$, incubation time, bacterial biomass, and growth medium, significantly affect mycotoxin removal by LAB [33]. Hsu et al. [52] demonstrated that the ability of the B. licheniformis strain CK1 to remove ZEA increased when the $\mathrm{pH}$ of the medium increased from 2.5 to 6.0. Wang et al. [53] also confirmed that ZEA removal by Lysinibacillus spp. is strictly dependent on several growth parameters, including $\mathrm{pH}$. In particular, a reduction in ZEA of close to $100 \%$ was observed at $37^{\circ} \mathrm{C}$ and $\mathrm{pH}$ 7.0. Further investigations are required to determine the optimal experimental conditions for ZEA removal by our viable LAB strains.

To the best of our knowledge, this is the first study to investigate the mycotoxin decontaminating activity of LAB strains in a LF model. Mycotoxins in LF can originate from contaminated raw feed materials used to prepare liquid formulations $[28,54,55]$. Few studies in the literature have addressed the use of LAB to reduce the mycotoxin concentration in food or feed. Some LAB have been found to effectively reduce the ZEA concentration by more than $50 \%$ in maize meal and maize porridge after 4 days of incubation $[56,57]$. A significant amount of $\alpha$-zearalenol was found after $24 \mathrm{~h}$ of incubation with different LAB species in a simulated corn silage model contaminated with ZEA [58], indicating that ZEA removal may lead to the formation of more toxic metabolites. ZEA metabolites (i.e., $\alpha$ - and $\beta$-zearalenol, zearalanone, and $\alpha$ - and $\beta$-zearalanol) were not detected in contaminated LF samples inoculated with our LAB strains. 
Table 4. Zearalenone (ZEA) removal by L. acidophilus CIP: 76.13T and L. delbrueckii subsp. bulgaricus CIP: $101027 \mathrm{~T}$ determined after 24 and $48 \mathrm{~h}$ of incubation in animal liquid feed (LF) at $37^{\circ} \mathrm{C}$. The microbial count at 0,24 , and $48 \mathrm{~h}$ is also reported. Values represent means \pm standard deviations of three independent experiments.

\begin{tabular}{cccccc}
\hline \multirow{2}{*}{ LAB Strain } & \multicolumn{2}{c}{ ZEA Reduction (\%) } & \multicolumn{3}{c}{ Log cfu/mL } \\
\cline { 2 - 5 } & $\mathbf{2 4} \mathbf{~ h}$ & $\mathbf{4 8 ~ h}$ & $\mathbf{0 ~ h}$ & $\mathbf{2 4} \mathbf{~ h}$ & $\mathbf{4 8 ~ h}$ \\
\hline $\begin{array}{c}\text { L. acidophilus CIP: 76.13T } \\
\text { L. delbrueckii subsp. bulgaricus CIP: }\end{array}$ & $14 \pm 2^{\mathrm{a}}$ & $22 \pm 2^{\mathrm{b}}$ & $5.6 \pm 0.1^{\mathrm{a}}$ & $7.5 \pm 0.1^{\mathrm{b}}$ & $5.6 \pm 0.8^{\mathrm{a}}$ \\
101027T & $10 \pm 2^{\mathrm{a}}$ & $23 \pm 2^{\mathrm{b}}$ & $5.8 \pm 0.1^{\mathrm{a}}$ & $9.5 \pm 0.6^{\mathrm{c}}$ & $8.9 \pm 1.1^{\mathrm{d}}$
\end{tabular}

Values within each group with different superscript letters are statistically different (ANOVA, Duncan test with $p<0.05$ representing significance).

\section{Conclusions}

This study examined the ability of two potential probiotic LAB strains, L. acidophilus CIP: 76.13T and L. delbrueckii subsp. bulgaricus CIP: 101027T, to remove mycotoxins (OTA, $\mathrm{ZEA}, \mathrm{DON}, \mathrm{AFB}_{1}$ ) in in vitro experiments and in an animal LF used as a feed model. An experimental procedure to study the mechanism of mycotoxin removal (adsorption or metabolism) by bacterial strains is presented. In particular, mechanisms involved in toxin decontamination by LAB strains were investigated by monitoring toxin reduction under different growth conditions (different media and presence or absence of nutrients) and in a different physiological state (viable or heat-inactivated cells), and by performing desorption trials (for ZEA only). As expected, the reduction percentage differed depending on the experimental conditions. In general, the mycotoxin removal ability observed for viable cells was higher compared with that obtained with heat-inactivated cells. For both strains, the highest reduction values were registered by viable cells for $\mathrm{AFB}_{1}$ in MRS (by ca. 30\%) and for ZEA and DON in PBS (by ca. 57 and 30\%, respectively). In contrast, the OTA concentration was not significantly affected. A binding mechanism is suggested to be responsible for OTA and $\mathrm{AFB}_{1}$ removal, while biodegradation may be responsible for reductions in DON and ZEA. A moderate level of ZEA removal was also found after 24 and $48 \mathrm{~h}$ of incubation in animal LF.

Although the mechanism of mycotoxin removal and the optimization of culture conditions for microbial growth need deeper investigation, the application of viable LAB cells with probiotic potential, in particular, L. acidophilus CIP: 76.13T, to the preparation of animal feed may help to counteract the toxic effects of mycotoxins and contribute to the maintenance of a healthy gastrointestinal tract.

\section{Materials and Methods}

\subsection{Chemicals and Reagents}

All chemicals used were of analytical grade. All solvents (HPLC grade) were purchased from J.T. Baker (Deventer, The Netherlands). Water was of MilliQ quality (Millipore, Bedford, MA, USA). Mycotoxin standards of $\mathrm{AFB}_{1}$, ZEA, OTA, and DON (purity >99\%) were purchased from Sigma Aldrich (Milan, Italy). Culture media were purchased from Oxoid S.p.A. (Garbagnate, Milan, Italy) unless otherwise specified.

Mycotoxin stock solutions of $\mathrm{AFB}_{1}, \mathrm{OTA}, \mathrm{ZEA}$, and DON $(1 \mathrm{mg} / \mathrm{mL})$ were prepared by dissolving solid commercial toxins in acetonitrile (HPLC grade) and stored in the dark at $4{ }^{\circ} \mathrm{C}$. The mycotoxin solutions used for the decontamination experiments and the calibrants used for the UHPLC analysis were prepared by diluting each stock solution in MRS (Merck, Germany), PBS, or UPLC mobile phase before use.

\subsection{Bacterial Strains and Culture Conditions}

L. acidophilus CIP: 76.13T and L. delbrueckii subsp. bulgaricus CIP: 101027T isolated from human urine and yogurt, respectively, were obtained from the Collection of Institute Pasteur (CIP; Paris, France). Strains were grown overnight on MRS at $37^{\circ} \mathrm{C}$ under microaerophilic conditions and shaken with 125 strokes/min unless otherwise mentioned. 
Fresh cultures were transferred in Nutrient Broth (NB, BioLifeItaliana, Milan, Italy) containing $20 \%$ glycerol $(w / v)$ and stored at $-80{ }^{\circ} \mathrm{C}$ until subsequent experiments.

\subsection{Effect of Mycotoxins on Microbial Growth}

Each strain was grown overnight in $5 \mathrm{~mL}$ of MRS at $37{ }^{\circ} \mathrm{C}$ under aerobic conditions and agitation (150 strokes/min). Fresh cultures were inoculated in MRS and incubated at $37^{\circ} \mathrm{C}$ to reach the optical density value at $600 \mathrm{~nm}$ (OD600) of $1.0 \pm 0.07$ (corresponding to $9.1 \pm 0.8 \log \mathrm{cfu} / \mathrm{mL}$, on average; mid-exponential growth phase). After dilution in sterile saline solution $(0.95 \% \mathrm{NaCl})$, each culture was inoculated in triplicate at $5.03 \pm 0.75 \log \mathrm{cfu} / \mathrm{mL}$ (on average) in MRS containing $1 \mu \mathrm{g} / \mathrm{mL}$ of each mycotoxin and incubated at $37^{\circ} \mathrm{C}$ under agitation (150 strokes/min) for 1, 2, 3, 4, 6, and $24 \mathrm{~h}$. At each incubation time, samples were analyzed for microbial enumeration by plating serial decimal dilutions onto MRS agar. Plates were incubated at $37^{\circ} \mathrm{C}$ for $24 \mathrm{~h}$ under conditions of aerobiosis.

\subsection{Mycotoxin Removal by Viable and Heat Inactivated LAB Cells}

Overnight $\mathrm{LAB}$ cultures, cultivated as described above, were inoculated (1\%) in $5 \mathrm{~mL}$ of MRS and incubated at $37{ }^{\circ} \mathrm{C}$ to reach the OD600 value of 0.6 , corresponding to $5-6 \log \mathrm{cfu} / \mathrm{mL}$. After that, the cultures were harvested by centrifugation $\left(13,000 \mathrm{rpm}\right.$ for $5 \mathrm{~min}$ at $\left.4{ }^{\circ} \mathrm{C}\right)$ and washed twice in sterile saline solution $(0.9 \% w / v \mathrm{NaCl})$.

To perform mycotoxin removal experiments using viable cells, the pellets were resuspended in $5 \mathrm{~mL}$ of MRS or sterile PBS supplemented with $1 \mu \mathrm{g} / \mathrm{mL}$ of each mycotoxin and incubated for $24 \mathrm{~h}$, as previously described. At the start and the end of the incubation period, the $\mathrm{pH}$ of cultures was determined with the Beckman Coulter $\Phi 340 \mathrm{pH} /$ TempMeter system (Fullerton, CA, USA). After the incubation period, samples were centrifuged for $10 \mathrm{~min}$ at $13,000 \mathrm{rpm}$.

In addition, mycotoxin reduction experiments were performed using inactivated LAB strains. LAB cells were inactivated as described by Piotrowska [44]. Briefly, LAB suspensions in PBS $(6 \log \mathrm{cfu} / \mathrm{mL})$ were autoclaved for $15 \mathrm{~min}$ at $121^{\circ} \mathrm{C}$ under $1 \mathrm{~atm}$ of pressure. Then, cells were recovered after centrifugation and resuspended in PBS or MRS and tested with mycotoxin removal experiments, as described above.

Mycotoxin removal experiments were performed in triplicate, and microbial loads were determined by plating decimal dilutions on MRS agar at the beginning and end of the incubation period. For each experiment, a control treatment without a bacterial strain (blank control) was subjected to the same test procedure and used as the background control during the analysis to investigate the stability of mycotoxins in MRS or PBS.

To measure the level of mycotoxin removal by each strain, supernatants of liquid cultures were analyzed by UPLC-FLD/PDA methods after a clean-up step using immunoaffinity columns from VICAM ${ }^{\odot}$ (Watertown, MA, USA). Briefly, $0.5 \mathrm{~mL}$ of each supernatant was diluted with PBS $(1.5 \mathrm{~mL})$ and cleaned up using an immunoaffinity column at a flow rate of about 1 drop per second. The column was first washed with $5 \mathrm{~mL}$ of PBS containing Tween $20(0.01 \%, v / v)$, followed by $5 \mathrm{~mL}$ of water. ZEA and DON were eluted with $2 \mathrm{~mL}$ of methanol in a $4 \mathrm{~mL}$ silanized amber vial. The eluates were dried at $50{ }^{\circ} \mathrm{C}$ under an air stream, and the residues were re-dissolved with $250 \mu \mathrm{L}$ of a mixture containing methanol and water $(20: 80, v / v)$ prior to UPLC injection. $\mathrm{AFB}_{1}$ and OTA were collected from the immunoaffinity columns with $1.5 \mathrm{~mL}$ of methanol. After the addition of $1.5 \mathrm{~mL}$ of water, samples were injected into the LC system. Mycotoxins were analyzed by UPLC using the method presented by Greco et al. [59] and Adunphatcharaphon et al. [60]. In addition, a UPLC-PDA method was used for the simultaneous determination of ZEA and its derived metabolites ( $\alpha$ - and $\beta$-zearalenol, $\alpha$ - and $\beta$-zearalanol, zearalanol). The apparatus was an ACQUITY UPLC ${ }^{\mathrm{TM}}$ system (Waters, MA, USA) combined with a PDA detector (PDA ACQUITY UPLC ${ }^{\circledR}$ ). The toxins were separated on a UPLC column (UPLC ${ }^{\circledR}$ BEH C18 column, $2.1 \times 100 \mathrm{~mm}, 1.7 \mu \mathrm{m})$ preceded by an in-line filter $(0.2 \mu \mathrm{m})$ under a gradient program. Water (solvent $\mathrm{A}$ ) and methanol (solvent $\mathrm{B}$ ) were used as mobile phases, with a flow rate of $0.35 \mathrm{~mL} / \mathrm{min}$. The gradient elution started with $15 \% \mathrm{~B}$, which 
was linearly increased to $100 \%$ in $23 \mathrm{~min}$. After elution, the column was re-equilibrated with $15 \%$ methanol for $10 \mathrm{~min}$. The column and the samples were maintained at constant temperatures of 50 and $15{ }^{\circ} \mathrm{C}$, respectively. The injection volume was $10 \mu \mathrm{L}$. The UV absorption spectra of toxins were recorded in the range of 190-400 nm. UV absorbance data were collected with a bandwidth of $1.2 \mathrm{~nm}$ and without digital filtering at a wavelength of $220 \mathrm{~nm}$.

The concentration of mycotoxins removed from liquid media was calculated as the difference between the concentration of mycotoxins in the supernatant of blank tubes with no $\mathrm{LAB}$ and the concentration found in the supernatant of the experimental tubes with LAB. This amount was then related to the quantity present in the supernatant of blank tubes and expressed as a percentage.

\subsection{Mycotoxin Desorption Experiments}

Desorption experiments were performed to determine the amount of toxin adsorbed onto the bacterial cells and released using an organic solvent. These tests allowed us to assess whether mycotoxin reduction by viable or inactivated LAB cells was due to an adsorption process or other mechanisms. The desorption study was performed for ZEA only, as this was the mycotoxin removed to the greatest extent by the tested LAB strains. First, the amount of ZEA removed by the bacterial pellets (containing viable or heat-inactivated cells) was measured. LAB suspensions of each strain (5-6 log cfu/mL) in PBS were incubated for $24 \mathrm{~h}$ in the presence of $1 \mu \mathrm{g} / \mathrm{mL}$ of the toxin. After incubation, the suspensions were centrifuged for $20 \mathrm{~min}$ at 14,000 rpm. The supernatants were completely removed and analyzed to determine their mycotoxin contents, as described above, to measure mycotoxin removal. The pellets were resuspended with $1 \mathrm{~mL}$ of a mixture containing acetonitrile and water $(90: 10, v / v)$ and incubated at $37^{\circ} \mathrm{C}$ for $60 \mathrm{~min}$ with soft agitation (150 stroke/min). At the end of the incubation period, samples were centrifuged, and $500 \mu \mathrm{L}$ of supernatant was dried under an air stream at ca. $50{ }^{\circ} \mathrm{C}$ and reconstituted with $500 \mu \mathrm{L}$ of a mixture containing water and methanol $(85: 15, v / v)$ before chromatographic injection. Desorption studies were performed in triplicate. To measure mycotoxin desorption, the amount of toxin released from the adsorbing cell pellets by the organic solvent was compared with the amount removed by the pellets from PBS and then expressed as a percentage.

\subsection{Mycotoxin Removal by LAB from Animal LF}

Taking into account the results of the preliminary study showing a $50 \%$ reduction of ZEA by LAB, the removal of this mycotoxin was investigated in a LF intended for weaning piglets. The main ingredients for the LF were kindly provided by the New Feed Team S.r.l. (Lodi, Italy): maize silage ( $\mathrm{pH} 4.5 ; 35 \%$ moisture) and dried feed (maize, soy, cereal bran vitamin and mineral mixture). The LF was prepared, as suggested by the New Feed Team S.r.l., by mixing the maize silage $(10 \%, w / v)$ with the dried feed $(10 \%, w / v)$ in distilled water $(80 \%, w / v)$ and stirring for $20 \mathrm{~min}$ at room temperature. Then, the mixture was autoclave-sterilized at $120{ }^{\circ} \mathrm{C}$ for $15 \mathrm{~min}$. After sterilization, the mixture was supplemented with sterilized water $(25 \% ; v / v)$ and stirred vigorously, to give a soft mixture for mycotoxin removal microbial tests. The latter steps (autoclavesterilizing, water supplementation and vigorous stirring) were required to remove naturally occurring microorganisms and to prepare a suitable LF for bacterial growth. ZEA reduction experiments were performed in sterile Falcon ${ }^{\circledR} 12$-welled polystyrene microplates (BD Biosciences, Erembodegem, Belgium). Sterilized LF containing $1 \mu \mathrm{g} / \mathrm{mL}$ of ZEA was inoculated with ca. $6 \mathrm{log} \mathrm{cfu} / \mathrm{mL}$ of each LAB strain. A volume $(2 \mathrm{~mL})$ of both inoculated and un-inoculated LF was dispensed into the 12-welled plate and fermented for 24 and $48 \mathrm{~h}$ at $37^{\circ} \mathrm{C}$ under aerobiosis and static conditions. Uninoculated LF supplemented with the toxin was used as a background control to investigate the stability of ZEA in LF and its unspecific binding to the components of the LF matrix. Test samples and controls were prepared as six independent replicates to be used for microbiological and chemical analyses (3 replicates each). 
To assess LAB growth in LF, the microbial load of the inoculated samples containing the toxin (or not) was measured after each incubation period. Thus, $2 \mathrm{~mL}$ of each LF sample was diluted with $18 \mathrm{~mL}$ of sterile saline solution $(0.9 \% \mathrm{NaCl})$, and these samples were homogenized and decimally diluted in sterile saline solution before plating on MRS agar ( $24 \mathrm{~h}, 37^{\circ} \mathrm{C}$ under aerobiosis) for enumeration.

To measure the removal of ZEA from contaminated LF by LAB strains, the toxin was analyzed according to the official method (ZEA: ISO 17372:2008) with a few changes [61]. Briefly, the LF cultures ( $2 \mathrm{~mL}$ each) were extracted in $50 \mathrm{~mL}$ Erlenmeyer flasks using $10 \mathrm{~mL}$ of a mixture containing water and acetonitrile $(10: 90, v / v)$. The flasks were incubated for $1 \mathrm{~h}$ at room temperature under soft agitation ( $150 \mathrm{stroke} / \mathrm{min})$. Then, the extracts were filtered using Whatman ${ }^{\circledR}$ filter papers (grade 4 ), and $1 \mathrm{~mL}$ of each extract was diluted with $4 \mathrm{~mL}$ of water. To clean up the samples, $1 \mathrm{~mL}$ of each diluted extract was passed through a ZearalaTest ${ }^{\mathrm{TM}}$ immunoaffinity column. After the washing step, the toxin was eluted with $2 \mathrm{~mL}$ of methanol. Cleaned-up samples in methanol were dried under an air stream at $50{ }^{\circ} \mathrm{C}$, reconstituted with a mixture containing water and methanol $(85: 15, v / v)$, and analyzed by UHPLC.

In order to check the ability of the method to analyze ZEA in LF samples, recovery and repeatability were determined by spiking LF with ZEA at two levels $(0.1$ and $1 \mu \mathrm{g} / \mathrm{mL})$ and analyzed as six independent replicates. These toxin levels were chosen to ensure the reliable analysis of mycotoxins in LF when a $90 \%$ reduction occurred. The concentrations of ZEA recovered from LF samples were determined by using a standard calibration curve. Repeatability was expressed as the relative standard deviation, $\operatorname{RSD}_{\mathrm{r}}(n=6)$.

\subsection{Statistical Analysis}

The effect of mycotoxins on bacterial growth was monitored in the presence and absence of each toxin, and the results were compared by using one-way ANOVA and the Dunnett test as post hoc analyses. The mycotoxin removal by LAB strains is expressed as the mean \pm standard deviation of three independent replicate experiments. Data were statistically analyzed by two-way ANOVA using statistical analysis software (Statistica 12.0, StatSoft ${ }^{\circledR}$ ). Two-way ANOVA was used to examine the influences of the medium and strains present on mycotoxin reduction. Post-hoc analyses of sample subgroups were performed using the Duncan test as a multiple comparison procedure. The significance level was set at 0.05 .

Supplementary Materials: The following are available online at https://www.mdpi.com/2072-6 651/13/3/185/s1, Table S1: Residual mycotoxin concentration ( $\mu \mathrm{g} / \mathrm{mL})$ in supernatant samples obtained by incubating viable (VC) and heat inactivated cells (HIC) of L. acidophilus CIP: 76.13T and L. delbrueckii supp. bulgaricu s CIP: 101027T with $1 \mu \mathrm{g} / \mathrm{mL}$ of each mycotoxin. Mycotoxin removal by LAB strains was determined in MRS and PBS after $24 \mathrm{~h}$ of incubation at $37{ }^{\circ} \mathrm{C}$ under aerobic conditions. AFB1: Aflatoxin B1, OTA: Ochratoxin A, ZEA: Zearalenone, DON: Deoxynivalenol., Table S2: Residual ZEA concentration in liquid feed (LF) obtained incubating viable cells of $L$. acidophilus CIP: $76.13 \mathrm{~T}$ and L. delbrueckii supp. bulgaricus CIP: $101027 \mathrm{~T}$ with $1 \mu \mathrm{g} / \mathrm{mL}$ of the toxin. ZEA removal in LF by LAB strains was determined after 24 and $48 \mathrm{~h}$ of incubation in LF at $37^{\circ} \mathrm{C}$. Microbial count at 0,24 and $48 \mathrm{~h}$ is also reported. Values represent means \pm standard deviations of three independent experiments.

Author Contributions: Conceptualization, C.R., G.A., L.Q., I.M.; Methodology, C.R., L.Q., D.G., V.D.; Validation, C.R., D.G., V.D.; Formal Analysis, C.R., L.Q., G.A., D.G., V.D., A.M., I.M., A.L.; Investigation, C.R., A.M., L.Q., D.G., V.D.; Resources, G.A., I.M.; Data Curation, C.R., L.Q., G.A.; Writing-Original Draft Preparation, C.R., A.M., L.Q., D.G., V.D.; Writing-Review \& Editing, G.A., L.Q.; Visualization, C.R., L.Q.; Supervision, G.A., A.M., L.Q.; Project Administration, G.A.; Funding Acquisition, G.A. All authors have read and agreed to the published version of the manuscript.

Funding: This research was funded by the CNR-ISPA and New Feed Team Project No. 2319 of 25/07/2019. The work was also supported by the Ministry of Higher Education and Scientific Research (Tunisia).

Institutional Review Board Statement: Not applicable. 
Informed Consent Statement: Not applicable.

Data Availability Statement: Not applicable.

Acknowledgments: The authors would like to thank the Institute of Sciences of Food Production (CNR-ISPA) for instrument and lab support; the Science Faculty of Bizerte, University of Carthage (Tunisia) for funding and materials support; and the New Feed Team S.r.l (Lodi, Italy) for liquid feed supply. The authors are grateful to Giuseppe Panzarini (CNR-ISPA) for his skilled technical support, and to Marinella Cavallo (CNR-ISPA) and Simonetta Martena (CNR-ISPA) for the administrative aid.

Conflicts of Interest: The authors declare no conflict of interest.

\section{References}

1. Binder, E.; Tan, L.; Chin, L.; Handl, J.; Richard, J. Worldwide occurrence of mycotoxins in commodities, feeds and feed ingredients. Anim. Feed. Sci. Technol. 2007, 137, 265-282. [CrossRef]

2. Richard, J.L. Some major mycotoxins and their mycotoxicoses-An overview. Int. J. Food Microbiol. 2007, 119, 3-10. [CrossRef]

3. Vila-Donat, P.; Marín, S.; Sanchis, V.; Ramos, A. A review of the mycotoxin adsorbing agents, with an emphasis on their multi-binding capacity, for animal feed decontamination. Food Chem. Toxicol. 2018, 114, 246-259. [CrossRef]

4. Zain, M.E. Impact of mycotoxins on humans and animals. J. Saudi Chem. Soc. 2011, 15, 129-144. [CrossRef]

5. Gruber-Dorninger, C.; Jenkins, T.; Schatzmayr, G. Global Mycotoxin Occurrence in Feed: A Ten-Year Survey. Toxins 2019, 11, 375. [CrossRef] [PubMed]

6. Streit, E.; Schwab, C.; Sulyok, M.; Naehrer, K.; Krska, R.; Schatzmayr, G. Multi-Mycotoxin Screening Reveals the Occurrence of 139 Different Secondary Metabolites in Feed and Feed Ingredients. Toxins 2013, 5, 504-523. [CrossRef] [PubMed]

7. European Commission. Commission Regulation No. 32/2002 of 7 May 2002 on undesirable substances in animal feed. Off. J. Eur. Union 2002. Available online: http:/ / data.europa.eu/eli/dir/2002/32/oj (accessed on 28 November 2019).

8. European Commission. Commission Recommendation No. 576 of 17 August 2006 on the presence of deoxynivalenol, zearalenone, ochratoxin A, T-2 and HT-2 and fumonisins in products intended for animal feeding. Off. J. Eur. Union 2006, L229, 7-9.

9. Streit, E.; Schatzmayr, G.; Tassis, P.; Tzika, E.; Marin, D.; Taranu, I.; Tabuc, C.; Nicolau, A.; Aprodu, I.; Puel, O.; et al. Current Situation of Mycotoxin Contamination and Co-occurrence in Animal Feed-Focus on Europe. Toxins 2012, 4, 788-809. [CrossRef]

10. Streit, E.; Naehrer, K.; Rodrigues, I.; Schatzmayr, G. Mycotoxin occurrence in feed and feed raw materials worldwide: Long-term analysis with special focus on Europe and Asia. J. Sci. Food Agric. 2013, 93, 2892-2899. [CrossRef]

11. Zhu, Y.; Hassan, Y.I.; Lepp, D.; Shao, S.; Zhou, T. Strategies and Methodologies for Developing Microbial Detoxification Systems to Mitigate Mycotoxins. Toxins 2017, 9, 130. [CrossRef]

12. Karlovsky, P.; Suman, M.; Berthiller, F.; De Meester, J.; Eisenbrand, G.; Perrin, I.; Oswald, I.P.; Speijers, G.; Chiodini, A.; Recker, T.; et al. Impact of food processing and detoxification treatments on mycotoxin contamination. Mycotoxin Res. 2016, 32, 179-205. [CrossRef] [PubMed]

13. Čolović, R.; Puvača, N.; Cheli, F.; Avantaggiato, G.; Greco, D.; Đuragić, O.; Kos, J.; Pinotti, L. Decontamination of MycotoxinContaminated Feedstuffs and Compound Feed. Toxins 2019, 11, 617. [CrossRef] [PubMed]

14. Loi, M.; Fanelli, F.; Zucca, P.; Liuzzi, V.C.; Quintieri, L.; Cimmarusti, M.T.; Monaci, L.; Haidukowski, M.; Logrieco, A.F.; Sanjust, E.; et al. Aflatoxin B1 and M1 Degradation by Lac2 from Pleurotus pulmonarius and Redox Mediators. Toxins 2016, 8, 245. [CrossRef]

15. Temba, B.; Sultanbawa, Y.; Kriticos, D.J.; Fox, G.P.; Harvey, J.J.W.; Fletcher, M.T. Tools for Defusing a Major Global Food and Feed Safety Risk: Nonbiological Postharvest Procedures to Decontaminate Mycotoxins in Foods and Feeds. J. Agric. Food Chem. 2016, 64, 8959-8972. [CrossRef] [PubMed]

16. Kabak, B.; Dobson, A.D.W.; Var, I. Strategies to Prevent Mycotoxin Contamination of Food and Animal Feed: A Review. Crit. Rev. Food Sci. Nutr. 2006, 46, 593-619. [CrossRef]

17. Jard, G.; Liboz, T.; Mathieu, F.; Guyonvarch, A.; Lebrihi, A. Review of mycotoxin reduction in food and feed: From prevention in the field to detoxification by adsorption or transformation. Food Addit. Contam. Part A 2011, 28, 1590-1609. [CrossRef]

18. Missotten, J.; Goris, J.; Michiels, J.; Van Coillie, E.; Herman, L.; De Smet, S.; Dierick, N.; Heyndrickx, M. Screening of isolated lactic acid bacteria as potential beneficial strains for fermented liquid pig feed production. Anim. Feed. Sci. Technol. 2009, 150, 122-138. [CrossRef]

19. Canibe, N.; Jensen, B.B. Fermented liquid feed-Microbial and nutritional aspects and impact on enteric diseases in pigs. Anim. Feed. Sci. Technol. 2012, 173, 17-40. [CrossRef]

20. Plumed-Ferrer, C.; Kivelä, I.; Hyvönen, P.; Von Wright, A. Survival, growth and persistence under farm conditions of a Lactobacillus plantarum strain inoculated into liquid pig feed. J. Appl. Microbiol. 2005, 99, 851-858. [CrossRef] [PubMed]

21. Missotten, J.A.; Michiels, J.; DeGroote, J.; De Smet, S. Fermented liquid feed for pigs: An ancient technique for the future. J. Anim. Sci. Biotechnol. 2015, 6, 1-9. [CrossRef] [PubMed]

22. Hong, J.S.; Jin, S.S.; Jung, S.W.; Fang, L.H.; Kim, Y.Y. Evaluation of dry feeding and liquid feeding to lactating sows under high temperature environment. J. Anim. Sci. Technol. 2016, 58, 36. [CrossRef] [PubMed] 
23. He, Y.; Mao, C.; Wen, H.; Chen, Z.; Lai, T.; Li, L.; Lu, W.; Wu, H. Influence of ad Libitum Feeding of Piglets with Bacillus Subtilis Fermented Liquid Feed on Gut Flora, Luminal Contents and Health. Sci. Rep. 2017, 7. [CrossRef]

24. Kantas, D.; Papatsiros, V.G.; Tassis, P.D.; Giavasis, I.; Bouki, P.; Tzika, E.D. A feed additive containing Bacillus toyonensis (Toyocerin $^{\circledR}$ ) protects against enteric pathogens in postweaning piglets. J. Appl. Microbiol. 2015, 118, 727-738. [CrossRef]

25. Yeo, S.; Lee, S.; Park, H.; Shin, H.; Holzapfel, W.; Huh, C.S. Development of putative probiotics as feed additives: Validation in a porcine-specific gastrointestinal tract model. Appl. Microbiol. Biotechnol. 2016, 100, 10043-10054. [CrossRef]

26. Rundberget, T.; Skaar, I.; Flåøyen, A. The presence of Penicillium and Penicillium mycotoxins in food wastes. Int. J. Food Microbiol. 2004, 90, 181-188. [CrossRef]

27. Sultana, N.; Hanif, N.Q. Mycotoxin contamination in cattle feed and feed ingredients. Pakistan Vet. J. 2019, $29,211-213$.

28. Adamse, P.; van Egmond, H.J.; Driessen, J.J.M.; de Rijk, T.C.; de Jong, J.; de Nijs, W.C.M. Trend Analysis of Mycotoxins in Animal Feed. Rikilt-Institute for Food Safety No. 2011.017. 2012. Available online: https:/ / edepot.wur.nl/197668 (accessed on 1 February 2012).

29. Cano-Garrido, O.; Seras-Franzoso, J.; Garcia-Fruitós, E. Lactic acid bacteria: Reviewing the potential of a promising delivery live vector for biomedical purposes. Microb. Cell Factories 2015, 14, 1-12. [CrossRef] [PubMed]

30. De Angelis, M.; Siragusa, S.; Caputo, L.; Ragni, A.; Burzigotti, R.; Gobbetti, M. Survival and persistence of Lactobacillus plantarum 4.1 and Lactobacillus reuteri $3 \mathrm{S7}$ in the gastrointestinal tract of pigs. Veter Microbiol. 2007, 123, 133-144. [CrossRef] [PubMed]

31. Vieco-Saiz, N.; Belguesmia, Y.; Raspoet, R.; Auclair, E.; Gancel, F.; Kempf, I.; Drider, D. Benefits and Inputs from Lactic Acid Bacteria and Their Bacteriocins as Alternatives to Antibiotic Growth Promoters During Food-Animal Production. Front. Microbiol. 2019, 10, 57. [CrossRef]

32. Rabelo, C.H.S.; Valente, A.L.S.; Barbero, R.P.; Basso, F.C.; Reis, R.A. Performance of finishing beef cattle fed diets containing maize silages inoculated with lactic-acid bacteria and Bacillus subtilis. Anim. Prod. Sci. 2019, 59, 266. [CrossRef]

33. Dalié, D.; Deschamps, A.; Richard-Forget, F. Lactic acid bacteria-Potential for control of mould growth and mycotoxins: A review. Food Control. 2010, 21, 370-380. [CrossRef]

34. Ahlberg, S.H.; Joutsjoki, V.; Korhonen, H.J. Potential of lactic acid bacteria in aflatoxin risk mitigation. Int. J. Food Microbiol. 2015, 207, 87-102. [CrossRef] [PubMed]

35. El-Nezami, H.; Gratz, S. Control of mycotoxin contamination in foods using lactic acid bacteria. In Protective Cultures, Antimicrobial Metabolites and Bacteriophages for Food and Beverage Biopreservation; Woodhead Publishing Series in Food Science, Technology and Nutrition; Elsevier: Amsterdam, The Netherlands, 2011; pp. 449-459.

36. Khosravi-Darani, K.; Sohrabvandi, S. Surface Binding of Toxins and Heavy Metals by Probiotics. Mini-Rev. Med. Chem. 2014, 14, 84-98. [CrossRef]

37. Chen, S.-W.; Wang, H.-T.; Shih, W.-Y.; Ciou, Y.-A.; Chang, Y.-Y.; Ananda, L.; Wang, S.-Y.; Hsu, J.-T. Application of Zearalenone (ZEN)-Detoxifying Bacillus in Animal Feed Decontamination through Fermentation. Toxins 2019, 11, 330. [CrossRef]

38. Vadopalas, L.; Ruzauskas, M.; Lele, V.; Starkute, V.; Zavistanaviciute, P.; Zokaityte, E.; Bartkevics, V.; Pugajeva, I.; Reinolds, I.; Badaras, S.; et al. Combination of Antimicrobial Starters for Feed Fermentation: Influence on Piglet Feces Microbiota and Health and Growth Performance, Including Mycotoxin Biotransformation in vivo. Front. Veter. Sci. 2020, 7, 528990. [CrossRef]

39. Ragoubi, C.; Quintieri, L.; Greco, D.; Mehrez, A.; Maatouk, I.; D’Ascanio, V.; Landoulsi, A.; Avantaggiato, G. Mycotoxin removal ability of Lactobacillus acidophilus cip 76.13 and L. brevis cip 102806t isolated from humans. J. Clin. Gastroent. 2020, 54, S29. [CrossRef]

40. Ali-Vehmas, T.; Rizzo, A.; Westermarck, T.; Atroshi, F. Measurement of Antibacterial Activities of T-2 Toxin, Deoxynivalenol, Ochratoxin A, Aflatoxin B1 and Fumonisin B1 Using Microtitration Tray-based Turbidimetric Techniques. J. Veter-Med. Ser. A 1998, 45, 453-458. [CrossRef] [PubMed]

41. Burmeister, H.R.; Hesseltine, C.W. Survey of the sensitivity of microorganisms to aflatoxin. Appl. Microbiol. 1966, 14, 403-404. [CrossRef] [PubMed]

42. Wang, J.-J.; Zhang, R.-Q.; Zhai, Q.-Y.; Liu, J.-C.; Li, N.; Liu, W.-X.; Li, L.; Shen, W. Metagenomic analysis of gut microbiota alteration in a mouse model exposed to mycotoxin deoxynivalenol. Toxicol. Appl. Pharmacol. 2019, 372, 47-56. [CrossRef] [PubMed]

43. Sadiq, F.A.; Yan, B.; Tian, F.; Zhao, J.; Zhang, H.; Chen, W. Lactic Acid Bacteria as Antifungal and Anti-Mycotoxigenic Agents: A Comprehensive Review. Compr. Rev. Food Sci. Food Saf. 2019, 18, 1403-1436. [CrossRef]

44. Piotrowska, M. The Adsorption of Ochratoxin A by Lactobacillus Species. Toxins 2014, 6, 2826-2839. [CrossRef] [PubMed]

45. Adebo, O.A.; Njobeh, P.B.; Gbashi, S.; Nwinyi, O.C.; Mavumengwana, V. Review on microbial degradation of aflatoxins. Crit. Rev. Food Sci. Nutr. 2017, 57, 3208-3217. [CrossRef]

46. Turbic, A.; Ahokas, J.T.; Haskard, C.A. Selective in vitro binding of dietary mutagens, individually or in combination, by lactic acid bacteria. Food Addit. Contam. 2002, 19, 144-152. [CrossRef]

47. Bueno, D.J.; Casale, C.H.; Pizzolitto, R.P.; Salvano, M.A.; Oliver, G. Physical Adsorption of Aflatoxin B1 by Lactic Acid Bacteria and Saccharomyces cerevisiae: A Theoretical Model. J. Food Prot. 2007, 70, 2148-2154. [CrossRef] [PubMed]

48. Chen, S.-W.; Hsu, J.-T.; Chou, Y.-A.; Wang, H.-T. The application of digestive tract lactic acid bacteria with high esterase activity for zearalenone detoxification. J. Sci. Food Agric. 2018, 98, 3870-3879. [CrossRef] [PubMed] 
49. Chlebicz, A.; Śliżewska, K. In Vitro Detoxification of Aflatoxin B1, Deoxynivalenol, Fumonisins, T-2 Toxin and Zearalenone by Probiotic Bacteria from Genus Lactobacillus and Saccharomyces cerevisiae Yeast. Probiotics Antimicrob. Proteins 2020, 12, $289-301$. [CrossRef] [PubMed]

50. García, G.R.; Payros, D.; Pinton, P.; Dogi, C.A.; Laffitte, J.; Neves, M.; Pereyra, M.L.G.; Cavaglieri, L.R.; Oswald, I.P. Intestinal toxicity of deoxynivalenol is limited by Lactobacillus rhamnosus RC007 in pig jejunum explants. Arch. Toxicol. 2017, 92, 983-993. [CrossRef]

51. Ben Taheur, F.; Fedhila, K.; Chaieb, K.; Kouidhi, B.; Bakhrouf, A.; Abrunhosa, L. Adsorption of aflatoxin B1, zearalenone and ochratoxin A by microorganisms isolated from Kefir grains. Int. J. Food Microbiol. 2017, 251, 1-7. [CrossRef] [PubMed]

52. Hsu, T.-C.; Yi, P.-J.; Lee, T.-Y.; Liu, J.-R. Probiotic characteristics and zearalenone-removal ability of a Bacillus licheniformis strain. PLoS ONE 2018, 13, e0194866. [CrossRef]

53. Wang, J.; Yang, F.; Yang, P.; Liu, J.; Lv, Z. Microbial reduction of zearalenone by a new isolated Lysinibacillus sp. ZJ-2016-1. World Mycotoxin J. 2018, 11, 571-578. [CrossRef]

54. Brooks, P.H.; Beal, J.D.; Niven, S. Liquid feeding of pigs: Potential for reducing environmental impact and for improving productivity and food safety. Recent Adv. Anim. Nutr. Aust. 2001, 13, 49-63.

55. Hurst, D.; Clarke, L.; Lean, I.J. Effect of liquid feeding at different water-to-feed ratios on the growth performance of growingfinishing pigs. Animal 2008, 2, 1297-1302. [CrossRef] [PubMed]

56. Mokoena, M.P.; Chelule, P.K.; Gqaleni, N. Reduction of Fumonisin B1 and Zearalenone by Lactic Acid Bacteria in Fermented Maize Meal. J. Food Prot. 2005, 68, 2095-2099. [CrossRef] [PubMed]

57. Chelule, P.; Mbongwa, H.; Carries, S.; Gqaleni, N. Lactic acid fermentation improves the quality of amahewu, a traditional South African maize-based porridge. Food Chem. 2010, 122, 656-661. [CrossRef]

58. Niderkorn, V.; Morgavi, D.P.; Pujos, E.; Tissandier, A.; Boudra, H. Screening of fermentative bacteria for their ability to bind and biotransform deoxynivalenol, zearalenone and fumonisins in anin vitrosimulated corn silage model. Food Addit. Contam. 2007, 24, 406-415. [CrossRef] [PubMed]

59. Greco, D.; D'Ascanio, V.; Santovito, E.; Logrieco, A.F.; Avantaggiato, G. Comparative efficacy of agricultural by-products in sequestering mycotoxins. J. Sci. Food Agric. 2019, 99, 1623-1634. [CrossRef]

60. Adunphatcharaphon, S.; Petchkongkaew, A.; Greco, D.; D'Ascanio, V.; Visessanguan, W.; Avantaggiato, G. The Effectiveness of Durian Peel as a Multi-Mycotoxin Adsorbent. Toxins 2020, 12, 108. [CrossRef]

61. International Organization for Standardization (ISO) 17372:2008. Animal Feeding Stuffs-Determination of Zearalenone by Immunoaffinity Column Chromatography and High-Performance Liquid Chromatography. Available online: https://www.iso. org/standard/43605 (accessed on 1 February 2008). 